\title{
Effect of Coping Strategies on Stress of Parent with Intellectual Disabilities Children
}

\author{
Bagher Ghobari Bonab ${ }^{1}$, Farzaneh Motamedi ${ }^{1} \&$ Fazlolah Zare $^{2}$ \\ ${ }^{1}$ Psychology College, Tehran University, Tehran, Iran \\ 2 Islamic Azad University Central Tehran Branch, Iran \\ Correspondence: Dr. Farzaneh Motamedi, Psychology College, Tehran University, Tehran, Iran.
}

Received: August 26, 2017

doi:10.20849/aes.v2i3.187
Accepted: September 25, 2017

Online Published: September 29, 2017

\begin{abstract}
Background: Raising a child with intellectual disability is stressful for the parent because it requires an intensive physical engagement as well as coping with emotional reactions to the child's condition. Parents have different modes of adapting to stress and demands caused by the disorder. Method: The current descriptive research design is aimed to identify existing coping strategies of parents who have children with intellectual disabilities. This study included 60 parents with intellectual disabilities children (30 mothers and 30 fathers) that were selected by random sampling. Parent's coping strategies were assessed by Collaborative Coping Strategies in Challenging Life Events (Ghobary et al., 2003) and Questionnaire on Resources and Stress (Friedrich, short form: QRS-F) was used to examine the degree of parental stress. Result: The correlation and regression analysis was used. The most of parent were used kind of coping strategies for coping with stress. Recognition of coping strategies of the parents is important and useful for the development of therapeutic interventions aimed at facilitating family adaptation in families with a child with intellectual disabilities.
\end{abstract}

Keywords: stress, parents, coping strategies, intellectual disabilities

\section{Introduction}

Parenting is a highly stressful job, and becoming a parent of a child with a disability is one of the most stressful life events that can occur. When a child is born with a disability, the unexpected and permanent nature of such an event generally increases a parent's vulnerability to stress. There is considerable evidence to suggest that parents of children with intellectual disabilities experience greater stress than parents of children without disabilities (Hastings \& Johnson, 2001). Research tells us that parents of disabled children are particularly vulnerable to stress. High levels of distress have been found in up to $70 \%$ of mothers and $40 \%$ of fathers of severely disabled children (Jones \& Passey, 2004). Thus, increased parental stress that leads to poor parental health and well-being, can negatively affect the health and well-being of the child. This sense of stress may be associated with a child's characteristics, greater financial and care-giving demands, feelings of being unprepared for the tasks of parenting, and a sense of loneliness and isolation (Sullivan-Bolyai, Sadler \& Knafl, 2003; Oruche, Gerkensmeyer, Stephan, Wheeler \& Hanna, 2012 \& Thwala, Ntinda \& Hlanze, 2015).

Current researches have reported that caring for a child with intellectual disabilities can be physically and mentally exhausting due to the demands of caring for the child around the clock. Due to the often complex health care needs of children with intellectual disabilities, parents are placed at an increased risk for high levels of stress, which can negatively affect overall health and well-being.

Though many studies indicate that parenting a child with intellectual disabilities can be a stressful experience (Grant \& Whittel, 2000; Gerstein, Crnic, Blacher \& Baker, 2009; Lloyd \& Hastings, 2008), it is not that every family will buckle under the stress of care giving (Felicity, Greerlan \& McClean, 2006; Gerstein et al., 2009; Neely-Barnes \& Dia, 2008) or hide the disabled child from others (Singh, Jahan, Nizamie, \& Singh, 2002). Rather, some may see it as an opportunity for extraordinary psychological growth (Trute \& Heiburt-Murphy, 2002 \& Ganjiwale, Ganjiwale, Sharma, \& Mishra, 2016). But it cannot be ascertained that the coping resources necessary for such adjustment are available to all. The facilitating factors and inhibiting factors of positive coping appear to include a set of sociocultural factors, parental characteristics and child's characteristics. Among the socio-cultural factors, poor socioeconomic status (Datta, Russell \& Gopalakrishna, 2002; Gupta \& Jain, 2002; 
Upadhyaya \& Havalappanavar, 2008a), ethnicity (Blacher, Baker \& MacLean, 2007) and rural domicile (Gupta \& Jain, 2002) were associated with stress. Though cultural beliefs are important, their effect seems to be related to how one interprets them.

Families of children with intellectual disabilities face diverse needs of the account of the disability in their children. Some of the prominent needs reported by the parents are related to personal care needs (Plant \& Sanders, 2007), management of adaptive behaviors (McCarthy, Cuskelly, Van Kraayenoord \& Cohen, 2006), medical (Neely-Barnes \& Marcenko, 2004), technical, financial and social needs (Verma \& Kishore, 2009). While these needs are common in the context of other disabilities and nondisabilities, the intensity of the above is usually very high and unique in intellectual disabilities (Peshawaria, 1995; Verma \& Kishore, 2009; James \& Ashwill, 2007 \& Peters \& Jackson, 2009).

If the parents and families are not supported in meeting their needs, it may further interfere with the development of a child, which in turn will create stressful situations for the parents and family (Azar \& Badr, 2006). In this context, it must be understood that parents' needs do not mean the personal needs of the parents, but the needs they experience for the child as is evident from several studies (Azar \& Badr, 2010; Kermanshahi et al., 2008; Verma and Kishore, 2009). The needs of the parents appear to depend on personal resources of the parents, family variables and the characteristics of children, and more importantly the socio-cultural setting to which the families belong. In general, parental age, marital status, and the number of intellectually disabled children in the family affected the outcome (Grant \& Whittell, 2000). Thus it is understood that there is no set pattern of needs except that they fall into multiple domains and multiple determinants. Within the context of parenting, the predominant view is that intellectual disabilities create stress and burden for the caregivers (Sethi, Bhargava, \& Dhiman, 2007). Additionally, parents may experience the impact of financial burden, restricted social interactions, and mental worries and so on (Alexander \& Walendzik, 2016).

However, recent research has shown that although some families are at risk for having numerous difficulties but many families positively cope and adapt to this stress (Mazibuko, 2011; Gona, Mung'ala-Odera, Newton \& Hartley, 2010; Durban, Rodriguez - Pabayos, Alontaga, Dolorfino-Arreza, \& Salazar, 2012).

Coping involves psychological resources and coping strategies that help to eliminate, modify, or manage a stressful event or crisis situation. Having a child with intellectual disabilities creates a crisis event, how parent respond to the stresses of raising their child with intellectual disabilities depends on a wide variety of factors influencing their ability to cope, such as their interpretation of the crisis event, the family's sources of support, community resources, and family structure. The personality characteristics of the family members, their financial status, educational level, problem-solving skills, and spirituality all influence a family's ability to cope. Strong marital relationship and social support also help determine parent adjustment (Emerson, 2003 \& Fazil, Wallace \& Singh, 2004; Thwala, Ntinda \& Hlanze, 2015). The goal of coping strategies is to strengthen or maintain family resources, reduce the source of stress or negative emotions, and achieve a balance in family functioning. Strategies directly aimed at coping with the source of stress, such as problem solving and seeking information are more adaptive strategies than those efforts to deny or minimize the situation (Bailey \& Smith, 2000). More ever, the literature on the adaptation of families of children with intellectual disabilities repeatedly indicates that it is important for service providers to understand family belief systems, both in a general sense and entity. Researchers document the importance of understanding families' worldviews, values and spiritual beliefs and day-to-day priorities and concerns (King, Baxter, Rosenbaum, Zwaigenbaum \& Bates, 2009). Because each family system is unique, each family may have different coping strategies. So, professionals need to know that what coping strategies are helping each family (Hockenberry \& Wilson, 2007 \& Woodgate, Aleah \& Seccol, 2008; King \& et al, 2009). Therefore, this research was to identify the coping strategies of parent who have children with intellectual disabilities and determine.

\section{Methodology}

\subsection{Research Design}

The current research design was a descriptive design aimed to identify the coping strategies of parent who have children with intellectual disabilities.

\subsection{Subjects}

The study involved 60 parents with intellectual disabilities children (30 mothers and 30 fathers) that were selected by random sampling.

\subsection{Instrument}

The data were collected using the following tools:- 


\section{(A) Questionnaire on Resources and Stress (QRS-F): (Friedrich \& et al., 1983).}

The original Questionnaire on Resources and Stress (QRS) (Holroyd, 1974) had 285 items and has been subject to a number of revisions that are shorter but maintain generally good reliability. In this research was used short form from Friedrich et al., 1983. QRS-F items are statements which deal with parents' feelings about their child, to which an answer of true or false is given (e.g.'Our family agrees on important matters';'I worry what will happen to $\mathrm{N}$ when I can no longer take care of him/her'). Reliability The Kuder-Richardson coefficients for mothers (0.85), and for both mothers (0.93) and fathers (0.88) (Honey, Hastings \& Mcconachie, 2005).

\section{(B) Collaborative Coping Strategies in Challenging Life Events}

To measure the variable "Reliance on God", the researchers employed the Collaborative Coping Strategies in Challenging Life Events (Ghobary Bonab, Khodayari-Fard, Shokoohi Yekta, Nasafat, 2003). This questionnaire poses 10 hypothetical situations which might happen in one's life (the situations sampled from the pool of citations drawn by the researcher). Participants' responses were measured in terms of "action", "attributions," and "feelings". The Collaborative Coping Strategies in Challenging Life Events consist of 130 Likert type items to which the participant responded by filling in the appropriate spaces. Subscales and the number of items on each are as follows: action, attribution, and feelings. Furthermore, this questionnaire has a high (Cronbach's Alpha) reliability coefficient of 0.88 for the action, 0.85 for the attribution, and an overall internal consistency of 0.92 . The validation study of this questionnaire is presented in detail in the final report of a research project (Ghobary Bonab, Khodayari-Fard, Shokoohi Yekta, Nasafat, 2003).

\section{Result}

Table 1. Types of coping strategies

\begin{tabular}{cccc}
\hline Coping strategies & $\mathrm{N}$ & Mean & $\mathrm{Sd}$ \\
\hline Personal & 60 & $36 / 43$ & $8 / 65$ \\
Natural & 60 & $42 / 32$ & $13 / 04$ \\
Delegated & 60 & $28 / 92$ & $10 / 26$ \\
Reliance & 60 & $39 / 72$ & $17 / 93$ \\
Social & 60 & $40 / 63$ & $11 / 51$ \\
\hline
\end{tabular}

Table 2. The regression analysis effect of coping strategies on reducing stress

\begin{tabular}{cccccc}
\hline & MS & df & Ss & F & sig \\
\cline { 2 - 6 } Mothers & $353 / 02$ & 5 & $70 / 60$ & $0 / 679$ & $0 / 643$ \\
Fathers & $155 / 30$ & 5 & $31 / 06$ & $0 / 634$ & $0 / 676$ \\
\hline
\end{tabular}

The amount of regression analysis was not significant and none of the coping strategies were effective in reducing the stress in mothers and fathers.

Table 3. Regression analysis effect of coping strategy of Delegated on Hope in parent

\begin{tabular}{|c|c|c|c|c|c|}
\hline & MS & $\mathrm{df}$ & Ss & $\mathrm{F}$ & sig \\
\hline Hope & $211 / 16$ & 1 & $211 / 16$ & $4 / 83$ & $0 / 032 *$ \\
\hline Error & $2535 / 68$ & 28 & $43 / 71$ & & \\
\hline Sum & $2746 / 85$ & 59 & & & \\
\hline \multirow{2}{*}{$\begin{array}{l}\text { Coping strategy } \\
\text { of Delegated }\end{array}$} & B & St.err & $\mathrm{b}$ & $\mathrm{t}$ & sig \\
\hline & $0 / 184$ & $0 / 084$ & $0 / 277$ & $2 / 198$ & $0 / 032^{*}$ \\
\hline
\end{tabular}

The strategy of delegated plays an important role in creating hope in parents. 
Table 4. Regression analysis effect of coping strategy of natural on relaxation

\begin{tabular}{cccccc}
\hline & MS & df & Ss & F & sig \\
\cline { 2 - 6 } Relaxation & $748 / 45$ & 1 & $748 / 45$ & $5 / 36$ & $0 / 024^{*}$ \\
Error & $8093 / 19$ & 58 & $139 / 53$ & & \\
Sum & $8841 / 65$ & 59 & $748 / 45$ & & sig \\
\hline Coping strategy & $\mathrm{B}$ & St.err & $\mathrm{b}$ & $\mathrm{t}$ & $0 / 024^{*}$ \\
\cline { 2 - 6 } of natural & $0 / 273$ & $0 / 118$ & $0 / 291$ & $2 / 316$ & \\
\hline
\end{tabular}

The value of $t(2 / 316)$ shows that coping strategy of natural significantly contributes to the relaxation of parents.

Table 5. Regression analysis effect of coping strategy of Reliance on patience

\begin{tabular}{cccccc}
\hline & MS & df & Ss & F & sig \\
\cline { 2 - 6 } Reliance & $361 / 47$ & 1 & $361 / 47$ & $5 / 41$ & $0 / 024^{*}$ \\
Error & $3875 / 37$ & 58 & $66 / 81$ & & \\
Sum & $4236 / 85$ & 59 & & t & sig \\
\hline Reliance & B & St.err & b & $2 / 326$ & $0 / 024$ \\
\cline { 2 - 6 } & $0 / 138$ & $0 / 059$ & $0 / 292$ & & \\
\hline
\end{tabular}

The $t$ value of coping strategy of reliance and its effect on patience and tolerance in parents shows that this strategy is significant and therefore it can be concluded that parents benefit from the coping strategy of reliance to create more patience and tolerance. This finding is consistent with our religious beliefs.

Table 6. Correlation of practical and attribution coping strategy

\begin{tabular}{clllll}
\hline $\begin{array}{c}\text { Attribution Coping } \\
\text { Practical Coping } \\
\downarrow\end{array}$ & Personal & Natural & Delegated & Reliance & Social \\
\hline Personal & $0 / 478^{* *}$ & $0 / 549^{* *}$ & $0 / 419^{* *}$ & $0 / 430^{* *}$ & $0 / 522^{* *}$ \\
Natural & $0 / 473^{* *}$ & $0 / 642^{* *}$ & $0 / 567^{* *}$ & $0 / 572^{* *}$ & $0 / 602^{* *}$ \\
Delegated & $0 / 322^{* *}$ & $0 / 544^{* *}$ & $0 / 748^{* *}$ & $0 / 753^{* *}$ & $0 / 505^{* *}$ \\
Reliance & $0 / 280^{* *}$ & $0 / 391^{* *}$ & $0 / 730^{* *}$ & $0 / 779^{* *}$ & $0 / 314^{* *}$ \\
Social & $0 / 364^{* *}$ & $0 / 561^{* *}$ & $0 / 470^{* *}$ & $0 / 503^{* *}$ & $0 / 613^{* *}$ \\
\hline
\end{tabular}

It can be concluded that all interactions between the matrix are meaningful and there is a significant relationship between attribution and practical coping strategies in the parents have children with intellectual disabilities. This data shows that the test of Collaborative Coping Strategies in Challenging Life Events the has high accuracy and validity.

\section{Conclusion and Discussion}

Parenting is one of the most challenging jobs an individual will ever face. Raising children can be stressful at times, but also very rewarding. Becoming the parent of a child who has a disability is a time of great stress and change (Thompson, 2000). A family's perception of having a child with a disability, the characteristics of the family, the family's internal and external resources, and the child's characteristics are all examples of factors that influence the amount of stress a family experiences. Coping is the family's attempt to manage or deal with the stressful situation. It is important that families learn how to deal with their stress effectively in order to avoid 
negative psychological, emotional, and physical consequences. The aims of this study were to identify the coping strategies of mothers who have children with intellectual disabilities. Regression analysis (table 2) showed effect of coping strategies on reducing of stress of mothers and fathers is not significant.

Also, the results of the current study revealed that effect of coping strategy of delegated on hope in parent (table 3 ); coping strategy of natural on relaxation (table 4) and coping strategy of reliance on patience (table 5) were significant. This finding is congruent with Mazibuko, 2011; Gona, Mung'ala-Odera, Newton \& Hartley, 2010; Durban \& et al, 2012; who reported that when caregivers are supported, they are better able to cope with the challenges of providing care for a child with special needs. In addition, this result is an agreement with Emerson, (2003); Fazil, Wallace \& Singh, (2004). Similarly, this is confirmed by Leung and Li-Tsang (2003) who reported that while it takes time for mothers to accept their children, as the children grow, mothers might feel pressure from society, especially on the occasions when their children exhibit unpredictable misbehavior in public, such as screaming. In order to avoid these embarrassments, mothers sometimes refrain from social activities. Thus, they limit their social networks. The results found that the correlation of practical and attribution coping strategy is significant (table 6). This result supported by Barentt \& et al (2003) who stated that having a wide variety of strategies is more helpful than having only one or two. Also, this finding shows that the test of Collaborative Coping Strategies in Challenging Life Events the has high accuracy and validity.

These findings suggest that mothers of children having intellectual disabilities suffer from significantly higher amount of stress and family burden. It appears that incompetency in taking care of these disabled children increases stress and family burden on parents. Therefore, special parent training programs should be provided to these parents to make them effective and competent in their parenting services and to help them control the behavior difficulties of their children which will in turn decrease their stress and family burden.

\section{References}

Alexander, \& Walendzik. (2016). Raising a child with Down syndrome: Do preferred coping strategies explain differences in parental health?. Psychology, 7, 28-39. https://doi.org/10.4236/psych.2016.71005

Azar, M., \& Badr, L.K. (2006). The adaptation of mothers of children with intellectual disability in Lebanon. Journal of Transcultural Nursing, 17, 375-380. https://doi.org/10.1177/1043659606291550

Azar, M., \& Badr, L.K. (2010). Predictors of coping in parents of children with an intellectual disability: comparison between Lebanese mothers and fathers. Journal of Pediatric Nursing, 25(1), 46-56. https://doi.org/10.1016/j.pedn.2008.11.001

Bailey, A. B., \& Smith, S. W. (2000). Providing effective coping strategies and supports for families with children with disabilities. Intervention in School and Clinic, 35(5), 294-296. https://doi.org/10.1177/105345120003500507

Blacher, J., Baker, B. L., \& MacLean, W.E. (2007). Positive impact of intellectual disability on families. American Journal on Mental Retardation, 112(5), 330-348. https://doi.org/10.1352/0895-8017(2007)112[0330:PIOIDO]2.0.CO;2

Datta, S. S., Russell, P. S. S., \& Gopalakrishna, S. C. (2002). Burden among the caregivers of children with intellectual disability: associations and risk factors. Journal of Learning Disabilities, 6(4), 337-350. https://doi.org/10.1177/146900470200600401

Durban, J. M., Rodriguez - Pabayos, A., Alontaga, J., Dolorfino-Arreza, G., \& Salazar, C. (2012). Coping strategies of parents of children with developmental delay: A quantitative analysis. Asian Journal of Social Science \& Humanities, 1(4), 177-195.

Emerson, E. (2003). Mothers of children and adolescents with intellectual disability: social and economic situation, mental health status, and the self- assessed social and psychological impact of the child's $\begin{array}{lllll}\text { difficulties. Intellectual Disabilities Research, } & 47(\mathrm{pt} \quad 4 / 5), & 385-399 .\end{array}$ https://doi.org/10.1046/j.1365-2788.2003.00498.x

Fazil, Q., Wallace, L. M., \& Singh, G. (2004). Empowerment and advocacy: reflection on action research with Bangladeshi and Pakistani families who have children with severe disabilities. Health Soc Care Community, 12(5), 389-397. https://doi.org/10.1111/j.1365-2524.2004.00508.x

Felicity, A., Greerlan, M., \& McClean, G. B. (2006). Coping and positive perceptions in Irish mothers of children with intellectual disabilities. Journal of Intellectual Disabilities, 10(3), 231-248. https://doi.org/10.1177/1744629506064017

Ganjiwale, D., Ganjiwale, J., Sharma, B., \& Mishra, B. (2016). Quality of life and coping strategies of caregivers 
of children with physical and mental disabilities. Journal of Family Medicine and Primary Care, 5(2), 343-348. https://doi.org/10.4103/2249-4863.192360

Gerstein, E. D., Crnic, K. A., Blacher, J., \& Baker, B. L. (2009). Resilience and the course of daily parenting stress in families of young children with intellectual disabilities. Journal of Intellectual Disability Research, 53(12), 981-997. https://doi.org/10.1111/j.1365-2788.2009.01220.x

Ghobary Bonab, B., Khodayari-Fard, M., Shokoohi Yekta, M., \& Nasafat, M. (2003). Taheye Miqyase Tawakkul be Khoda [Development of Reliance on God Scale.] Approved project of the University of Tehran (unpublished). (Persian).

Gona, J. K., Mung'ala-Odera, V., Newton, C. R., \& Hartley, S. (2010). Caring for children with disabilities in Kilifi Kenya: What is the career's experience?. Child: Care, Health, and Development, 37(2), $175-183$. https://doi.org/10.1111/j.1365-2214.2010.01124.x

Grant, G., \& Whittell, B. (2000). Differentiated coping strategies in families with children or adults with intellectual disabilities: the relevance of gender, family composition and the life span. Journal of Applied Research in Intellectual Disabilities, 13(4), 256-275. https://doi.org/10.1046/j.1468-3148.2000.00035.x

Gupta, M., \& Jain, M. (2002). A study of problems of parents about their mentally retarded children with spastic cerebral palsy. Disabilities and Impairments, 16, 123-128.

Hastings, R. P., \& Johnson, E. (2001). Stress in UK families conducting intensive home-based behavioral intervention for their young child with autism. Journal of Autism and Developmental Disorders, 31, 327-336. https://doi.org/10.1023/A:1010799320795

Hockenberry, M., \& Wilson, D. (2007). Wong's nursing care of infants and children (8th ed.). Elsevier Mosby Company: Canada, Chapter 22, PP. 921-956.

Honey, E., Hastings, R., \& Mcconachie, H. (2005). Use of the Questionnaire on Resources and Stress (QRS-F) with parents of young children with autism. The National Autistic Society, 9(3), $243-252$. https://doi.org/10.1177/1362361305053256

James, S. R., \& Ashwill, J. W. (2007). Nursing Care of Children (3rd ed.). Saunders: Elsevier, Chapter 12, PP. 306-371.

Jones, J., \& Passey, J. (2004). Family Adaptation, Coping and Resources: Parents of Children With Developmental Disabilities and Behavior Problems. Journal on Developmental Disabilities, 11(1), 31-45.

Kermanshahi, S. M., Vanaki, Z., Ahmadi, F., Kazemnejad, A., Mordoch, E., \& Azadfalah, P. (2008). Iranian mothers' perceptions of their lives with children with mental retardation: a preliminary phenomenological investigation. Journal of Developmental and Physical Disabilities, 20(4), 317-326. https://doi.org/10.1007/s10882-008-9099-3

King, G., Baxter, D., Rosenbaum, P., Zwaigenbaum, L., \& Bates, A. (2009). Belief systems of families of children with autism spectrum disorders or down Syndrome. Developmental Disabilities, 24(1), $50-64$. https://doi.org/10.1177/1088357608329173

Leung, Y. S., \& Li-Tsang, P. W. (2003). Quality of life of parents who have children with disabilities. Hong Kong Journal of Occupational Therapy, 13(1), 19-24. https://doi.org/10.1016/S1569-1861(09)70019-1

Lloyd, T., \& Hastings, R. P. (2008). Psychological variables as correlates of adjustment in mothers of children with intellectual disabilities: cross-sectional and longitudinal relationships. Journal of Intellectual Disability Research, 52(1), 37-48.

Mazibuko, G. F. (2011). The received training and psychosocial needs of parents of children with special needs in Nhlangano Area, in the Shiselweni region (Unpublished master's thesis). University of Swaziland, Kwaluseni, Swaziland.

McCarthy, A., Cuskelly, M., Van Kraayenoord, C. E., \& Cohen, J. (2006). Predictors of stress in mothers and fathers of children with Fragile X Syndrome. Research in Developmental Disabilities, 27(6), 688-704. https://doi.org/10.1016/j.ridd.2005.10.002

Neely-Barnes, S. L., \& Dia, D. A. (2008). Families of children with disabilities: a review of literature and recommendations for interventions. Journal of Early and Intensive Behavior Intervention, 5(3), 93-107. https://doi.org/10.1037/h0100425

Neely-Barnes, S. L., \& Marcenko, M. (2004). Predicting impact of childhood disability on families: Results from 
the 1995 National Health Interview Survey Disability Supplement. Mental Retardation, 42(4), 284-293. https://doi.org/10.1352/0047-6765(2004)42<284:PIOCDO>2.0.CO;2

Oruche, U. M., Gerkensmeyer, J., Stephan, L., Wheeler, C. A., \& Hanna, K. M. (2012). The Described Experience of Primary Caregivers of Children With Mental Health Needs. Archives of Psychiatric Nursing, 26(5), 382-391. https://doi.org/10.1016/j.apnu.2011.12.006

Peshawaria, R., Menon, D.K., Ganguly, R., Roy, S., Pillay, R. P. R. S., \& Gupta, A. (1995). Understanding Indian families having persons with mental retardation. Secunderabad, India: National Institute for the Mentally Handicapped.

Peters, K., \& Jackson, D. (2009). Mothers' experiences of parenting a child with attention deficit hyperactivity disorder. Journal of Advanced Nursing, 65, 62-71. https://doi.org/10.1111/j.1365-2648.2008.04853.x

Plant, K. M., \& Sanders, M. R. (2007). Care-giver stress in families of preschool-aged children with developmental disabilities. Journal of Intellectual Disability Research 51(2), 109-124. https://doi.org/10.1111/j.1365-2788.2006.00829.x

Sethi, S., Bhargava, S. C., \& Dhiman, V. (2007). Study of Level of Stress and Burden in the Caregivers of Children with Mental Retardation. Eastern Journal of Medicine 12(1-2), 21-24.

Singh, H., Jahan, M., Nizamie, A., \& Singh, V. K. (2002). Impact of mentally challenged children on family: parent's report. Indian Journal of Clinical Psychology, 29(2), 126-129.

Sullivan-Bolyai, S., Sadler, L., \& Knafl, K. A. (2003). Great expectations: a position description for parents as caregivers: Part I. Journal of Pediatric Nursing, 30(1), 52-56.

Thompson, C.E. (2000). Raising a handicapped child. New York, NY.

Thwala, S. K., Ntinda, K., \& Hlanze, B. (2015). Lived Experiences of Parents' of Children with Disabilities in Swaziland. Journal of Education and Training Studies, 3(4), 206-215. https://doi.org/10.11114/jets.v3i4.902

Trute, B., \& Heiburt-Murphy, D. (2002). Family adjustment to childhood developmental disability: a measure of parental appraisal of family impact. Journal of Pediatric Psychology, 23, 271-280. https://doi.org/10.1093/jpepsy/27.3.271

Upadhyaya, G. R., \& Havalappanavar, N. B. (2008b). Coping in parents of the mentally challenged. Journal of the Indian Academy of Applied Psychology, 34(2), 221-225.

Verma, R. K., \& Kishore, M. T. (2009). Needs of Indian parents having children with intellectual disability. International Journal of Rehabilitation Research, 32(1), 71-76. https://doi.org/10.1097/MRR.0b013e32830d36b6

Woodgate, R. L., Aleah, C., \& Seccl, L. (2008). Living in a world of our own: The experience of parents who have a child with autism. Qualitative Health Research, 18(8), 1075-1083. https://doi.org/10.1177/1049732308320112

\section{Copyrights}

Copyright for this article is retained by the author(s), with first publication rights granted to the journal.

This is an open-access article distributed under the terms and conditions of the Creative Commons Attribution license (http://creativecommons.org/licenses/by/4.0/). 